\title{
Ventilatory and heart rate responses to hypoxia and hypercapnia in patients with diabetes mellitus
}

\author{
M NISHIMURA, K MIYAMOTO, A SUZUKI, H YAMAMOTO, M TSUJI, F KISHI, \\ Y KAWAKAMI
}

From the First Department of Medicine, School of Medicine, Hokkaido University, Sapporo, Japan

\begin{abstract}
The ventilatory response to isocapnic progressive hypoxia and hyperoxic progressive hypercapnia in 24 diabetic patients were compared with those of sex and age matched normal control subjects. The heart rate response to hypoxia was also measured in both groups. In diabetic patients the ventilatory and heart rate responses to hypoxia were significantly lower than those in the control group $\left(0.10 v 0.241 / \mathrm{min} / \%\right.$ fall $/ \mathrm{m}^{2}$ and $0.51 v 1.27$ beats $/ \mathrm{min} / \%$ fall respectively). The ventilatory response to hypercapnia was significantly higher $\left(1.09 v 0.761 / \mathrm{min} / \mathrm{mm} \mathrm{Hg} / \mathrm{m}^{2}\right)$ in the diabetic patients. There was a significant correlation between the hypoxic ventilatory response and the heart rate response in diabetic patients $(r=0.56)$, but not in the control group $(r=0.28)$. In addition, both the ventilatory and the heart rate responses to hypoxia in diabetic patients had weak but significant correlations with the heart rate variation during deep breathing. It is concluded that the ventilatory and heart rate responses to hypoxia in diabetic patients are impaired, whereas the ventilatory response to hypercapnia is well preserved.
\end{abstract}

\section{Introduction}

Autonomic neuropathy is recognised as an important complication of diabetes, and has a considerable morbidity and a poor prognosis. ${ }^{1}$ Unexplained cardiorespiratory arrest has been reported in patients with this complication, and defective respiratory or cardiovascular reflexes have been postulated as aetiological factors. ${ }^{23}$ Sleep apnoea has also been reported to be more frequent in diabetic patients with autonomic neuropathy than in those without autonomic neuropathy, suggesting disordered ventilatory control. ${ }^{4}$

Whether the ventilatory responses to hypoxia or hypercapnia are impaired in patients with autonomic neuropathy is still debated. ${ }^{5-9}$ The substantial variability in the ventilatory response to hypoxia and hypercapnia among normal individuals may mask differences between patients and normal controls, particularly when small numbers are studied.

In the present study we selected a large random

\footnotetext{
Address for reprint requests: Dr M Nishimura, First Department of Medicine, School of Medicine, Hokkaido University, Sapporo 060, Japan.
}

Accepted 11 January 1989 group of diabetic patients with various degrees of neuropathy, and compared their ventilatory responses to hypoxia and hypercapnia with those of sex and age matched healthy control subjects. We also measured the heart rate response to hypoxia. In the diabetic patients we examined the relation between the ventilatory and heart rate responses and the presence of symptoms or objective evidence of autonomic neuropathy as assessed by the heart rate variation during deep breathing.

\section{Methods}

PATIENTS AND CONTROL SUBJECTS

Fourteen insulin dependent diabetic and 10 noninsulin dependent diabetic patients were included in the study. All patients were randomly selected from the weekly diabetic outpatient clinic or from patients who were in hospital for assessment and education. All were clinically stable and none had any evidence of cardiopulmonary disease at the time of the study. Twenty four healthy normal subjects with no history of diabetes mellitus or cardiopulmonary disease acted as control subjects. The controls were chosen so that their sex ratio and age distribution were similar to those of the patients. Anthropometric data on the patients and normal control subjects are shown in 
Table 1 Physical characteristics of the diabetic patients and control subjects (mean (SD) values)

\begin{tabular}{|c|c|c|c|c|c|}
\hline & Sex & $\begin{array}{ll} & \text { Age } \\
n(y) & (y)\end{array}$ & $\begin{array}{l}\text { Height } \\
(\mathrm{cm})\end{array}$ & $\begin{array}{l}\text { Weight } \\
(\mathrm{kg})\end{array}$ & $\begin{array}{l}B S A \\
\left(m^{2}\right)\end{array}$ \\
\hline $\begin{array}{l}\text { Diabetic } \\
\text { patients }\end{array}$ & $\begin{array}{l}\mathbf{M} \\
\mathbf{F}\end{array}$ & $\begin{array}{l}1445.9(13 \cdot 1) \\
1048.5(10 \cdot 6)\end{array}$ & $\begin{array}{l}167 \cdot 0(6 \cdot 9) \\
152 \cdot 1(5 \cdot 7)\end{array}$ & $\begin{array}{l}58.6(7.6)^{*} \\
49.9(9 \cdot 4)\end{array}$ & $\begin{array}{l}1.65(0.13)^{*} \\
1.44(0.12)\end{array}$ \\
\hline $\begin{array}{l}\text { Normal } \\
\text { subjects }\end{array}$ & $\begin{array}{l}\mathrm{M} \\
\mathrm{F}\end{array}$ & $\begin{array}{ll}14 & 44.3 \\
10 & 48.0(11 \cdot 5) \\
(9 \cdot 3)\end{array}$ & $\begin{array}{l}167 \cdot 2(4 \cdot 5) \\
152 \cdot 1(4 \cdot 6)\end{array}$ & $\begin{array}{l}66 \cdot 3(7 \cdot 7) \\
53 \cdot 7(8 \cdot 5)\end{array}$ & $\begin{array}{l}1.75(0.10) \\
1.49(0.12)\end{array}$ \\
\hline
\end{tabular}

BSA-body surface area.

${ }^{*} p<0.05$ in the comparison with the values in normal subjects.

table 1. Informed consent was obtained from each subject.

The clinical features of the patients are shown in table 2. "Duration of diabetes" indicates the time from the initial diagnosis. Retinopathy was classified in two categories, background retinopathy and proliferative retinopathy. Nephropathy was regarded as present when urine analysis repeatedly showed proteinuria $(>0.3 \mathrm{~g} / \mathrm{l})$. Peripheral neuropathy was diagnosed in patients with absent tendon reflexes and impaired appreciation of vibration, touch, or pain. Orthostatic hypotension was considered to be present if systolic arterial blood pressure fell by $20 \mathrm{~mm} \mathrm{Hg}$ or more when the patient was standing. None of the patients was receiving medication for hypertension, although two had borderline hypertension.
MEASUREMENTS

Forced vital capacity (FVC) and forced expiratory volume in one second $\left(\mathrm{FEV}_{1}\right)$ were measured with a bellows type spirometer (Chestac STM 81, Chest Products) at least one hour before the study of ventilatory responses, and the results were expressed as percentages of the predicted values. ${ }^{11} 11$ With the subject supine and breathing through a mouthpiece, arterial blood samples were drawn from the brachial artery for oxygen and carbon dioxide estimation $\left(\mathrm{PaO}_{2}\right.$ and $\left.\mathrm{PaCO}_{2}\right)$ and $\mathrm{pH}$ analysis $(\mathrm{pH} /$ blood gas analyser type 813; Instrumentation Laboratory). The ventilatory responses to hypoxia and hypercapnia were measured with a "dual control machine."12 Briefly, the machine automatically changes inspiratory gas composition to maintain a constant end tidal $\mathrm{PO}_{2}$ or $\mathrm{PCO}_{2}$. Minute ventilation ( $(\dot{V} E)$ was sampled every 15 seconds by electrical integration of the flow signals obtained from a hot wire respiratory flowmeter (Minato Medical Products, RF-H). Expired gas concentrations were monitored continuously by a mass spectrometer (MGA 1100, Perkin-Elmer Medical Instruments). Arterial oxygen saturation $\left(\mathrm{SaO}_{2}\right)$ was measured with a fingertip oximeter (MET-1471, Mochida-Minolta). The electrical signals of end tidal $\mathrm{PO}_{2}$ and $\mathrm{PCO}_{2}\left(\mathrm{PetO}_{2}\right.$ and $\mathrm{PetCO}_{2}$ ), $\mathrm{VE}, \mathrm{SaO}_{2}$, and heart rate (HR) were monitored and recorded on a multichannel recorder (Sanei-Sokki 142-8), and also stored at 15 second

Table 2 Clinical features of the diabetic patients

\begin{tabular}{|c|c|c|c|c|c|c|c|c|c|c|c|}
\hline $\begin{array}{l}\text { Patient } \\
\text { No }\end{array}$ & $\begin{array}{l}\text { Age } \\
(y)\end{array}$ & Sex & $\begin{array}{l}\text { Duration } \\
\text { (y) of } \\
\text { diabetes }\end{array}$ & $\begin{array}{l}\text { Retino- } \\
\text { pathy }\end{array}$ & $\begin{array}{l}\text { Nephro- } \\
\text { pathy }\end{array}$ & $\begin{array}{l}\text { Peripheral } \\
\text { neuropathy }\end{array}$ & $\begin{array}{l}\text { Orthostatic } \\
\text { hypotension }\end{array}$ & $\begin{array}{l}\text { Insulin } \\
\text { dependence }\end{array}$ & $\begin{array}{l}\text { Glycosylated } \\
\text { haemoglobin } \\
(\%)\end{array}$ & $\begin{array}{l}\text { Fasting } \\
\text { plasma } \\
\text { glucose } \\
(\mathrm{mg} / \mathrm{dl})\end{array}$ & $\begin{array}{l}\Delta H R \\
\text { (beats/min) }\end{array}$ \\
\hline $\begin{array}{r}1 \\
2 \\
3 \\
4 \\
5 \\
6 \\
7 \\
8 \\
9 \\
10 \\
11 \\
12 \\
13 \\
14 \\
15 \\
16 \\
17 \\
18 \\
19 \\
20 \\
21 \\
22 \\
23 \\
24\end{array}$ & $\begin{array}{l}61 \\
27 \\
21 \\
37 \\
41 \\
43 \\
43 \\
55 \\
42 \\
57 \\
44 \\
46 \\
50 \\
47 \\
60 \\
56 \\
50 \\
45 \\
65 \\
35 \\
43 \\
68 \\
61 \\
31\end{array}$ & $\begin{array}{l}\mathbf{F} \\
\mathbf{M} \\
\mathbf{M} \\
\mathbf{F} \\
\mathbf{F} \\
\mathbf{M} \\
\mathbf{F} \\
\mathbf{M} \\
\mathbf{M} \\
\mathbf{M} \\
\mathbf{F} \\
\mathbf{M} \\
\mathbf{F} \\
\mathbf{M} \\
\mathbf{M} \\
\mathbf{F} \\
\mathbf{F} \\
\mathbf{M} \\
\mathbf{M} \\
\mathbf{F} \\
\mathbf{M} \\
\mathbf{F} \\
\mathbf{M} \\
\mathbf{M}\end{array}$ & $\begin{array}{r}4 \\
12 \\
6 \\
14 \\
9 \\
11 \\
11 \\
11 \\
15 \\
5 \\
18 \\
10 \\
1 \\
8 \\
15 \\
2 \\
1 \\
1 \\
1 \\
9 \\
11 \\
4 \\
1 \\
1\end{array}$ & $\begin{array}{l}O \\
\text { PF } \\
\text { BG } \\
\text { PF } \\
O \\
\text { BG } \\
O \\
\text { PF } \\
\text { PF } \\
O \\
\text { PF } \\
\text { PF } \\
\text { BG } \\
O \\
O \\
\text { BG } \\
O \\
O \\
O \\
O \\
\\
\text { PF } \\
O \\
O \\
O\end{array}$ & $\begin{array}{l}- \\
+ \\
- \\
+ \\
- \\
- \\
- \\
- \\
- \\
- \\
+ \\
+ \\
- \\
- \\
- \\
+ \\
- \\
- \\
- \\
- \\
+ \\
- \\
- \\
-\end{array}$ & $\begin{array}{l}- \\
+ \\
- \\
- \\
- \\
- \\
- \\
- \\
- \\
+ \\
+ \\
+ \\
- \\
- \\
- \\
- \\
- \\
- \\
+ \\
+ \\
- \\
-\end{array}$ & $\begin{array}{l}- \\
+ \\
+ \\
- \\
- \\
- \\
- \\
+ \\
- \\
- \\
+ \\
+ \\
- \\
- \\
+ \\
+ \\
- \\
- \\
- \\
+ \\
+ \\
- \\
-\end{array}$ & $\begin{array}{l}+ \\
+ \\
+ \\
+ \\
+ \\
- \\
+ \\
+ \\
+ \\
+ \\
+ \\
+ \\
- \\
- \\
- \\
- \\
- \\
- \\
+ \\
+ \\
- \\
+ \\
+\end{array}$ & $\begin{array}{r}11.7 \\
15.4 \\
14.6 \\
6.0 \\
13.7 \\
12.0 \\
12.8 \\
13.6 \\
11.3 \\
13.0 \\
7.6 \\
12.3 \\
11.9 \\
12.5 \\
14.2 \\
10.8 \\
12.6 \\
12.4 \\
10.7 \\
14.8 \\
14.9 \\
12.5 \\
11.9 \\
13.8\end{array}$ & $\begin{array}{r}116 \\
384 \\
172 \\
100 \\
233 \\
194 \\
177 \\
148 \\
268 \\
92 \\
169 \\
253 \\
172 \\
170 \\
210 \\
145 \\
192 \\
198 \\
162 \\
182 \\
189 \\
110 \\
121 \\
70\end{array}$ & $\begin{array}{r}6.8 \\
4.6 \\
11.0 \\
3.9 \\
11.8 \\
15 \cdot 1 \\
12.8 \\
19.6 \\
21 \cdot 5 \\
13.7 \\
3.4 \\
4.6 \\
13.1 \\
10.1 \\
12.8 \\
4.9 \\
6.4 \\
10.1 \\
24.1 \\
25.3 \\
4.3 \\
3.3 \\
9.5 \\
13.4\end{array}$ \\
\hline
\end{tabular}

BG-background; $P F$ - proliferative; $\triangle H R$ - heart rate variation during deep breathing. See text for definitions of duration of diabetes, nephropathy, peripheral neuropathy, and orthostatic hypotension. 
intervals in an online signal processing computer (Nihon Kohden ATAC-450) for later analysis. Isocapnic hypoxia was attained by progressively lowering Peto $_{2}$ from 100 to $40 \mathrm{~mm} \mathrm{Hg}^{*}$ over 6-7 minutes while $\mathrm{PetCO}_{2}$ was kept constant at the resting level. The hypoxic ventilatory response was assessed as change in $\dot{\mathrm{V}} \mathrm{E}$ against change in $\mathrm{SaO}_{2}\left(\Delta \dot{\mathrm{V}} \mathrm{E} / \Delta \mathrm{SaO}_{2}\right)$, on the basis of a linear relation between $\dot{\mathrm{V}}$ and $\mathrm{SaO}_{2}$, the least squares method being used. The relation of change in heart rate to change in $\mathrm{SaO}_{2}\left(\Delta \mathrm{HR} / \Delta \mathrm{SaO}_{2}\right)$ was used to measure the heart rate response to hypoxia, given a linear relation between heart rate and $\mathrm{SaO}_{2} \cdot{ }^{14}$ For hyperoxic hypercapnia the fractional concentration of carbon dioxide initially inspired $(5 \%)$ was increased gradually over 5-6 minutes to attain the predetermined $\mathrm{PetCO}_{2}(55 \mathrm{~mm} \mathrm{Hg})$, while Peto ${ }_{2}$ was maintained at $200 \mathrm{~mm} \mathrm{Hg}$. The hypercapnic ventilatory response was measured as the slope factor, $\mathrm{S}$, which is derived from the equation $\dot{\mathrm{VE}}=\mathrm{S}\left(\mathrm{P}_{\mathrm{ET}} \mathrm{CO}_{2}-\mathrm{B}\right)$, where $\mathrm{B}$ is the intercept of the $\dot{\mathrm{VE}}-\mathrm{P}_{\mathrm{ET}} \mathrm{CO}_{2}$ line. Ventilatory response was standardised for body surface area, a known determinant of ventilatory responses, ${ }^{13}$ because the mean body surface area in the diabetic patients was smaller than that in the control group. The time interval between the two measurements was about 30 minutes.

About 30 minutes before the measurement of the ventilatory response subjects with diabetes mellitus rested supine for at least 10 minutes. Once a stable heart rate had been obtained they were asked to breathe deeply at a rate of 6 breaths $/ \min (5 \mathrm{~s}$ in, $5 \mathrm{~s}$ out) for two minutes while their heart rate was monitored continuously. Heart rate variation during deep breathing $(\Delta \mathrm{HR})$ was assessed by measuring the difference between the maximum and the minimum heart rate (in beats/min) over 10 breaths, the average from 10 full breaths being recorded.

All tests were performed in the afternoon. Subjects had their usual lunch at least two hours before the tests and they were requested to abstain from coffee or tea, cigarettes, and any drugs except insulin and other diabetic medications.

$* 1 \mathrm{~mm} \mathrm{Hg} \approx 0.133 \mathrm{kPa}$.

\section{STATISTICAL ANALYSES}

Differences between group means were examined by the unpaired Student's $t$ test. A linear correlation coefficient ( $r$ ) between two variables was calculated and $t$ values were obtained from the equation:

$t=r^{2}(n-2)\left(1-r^{2}\right)$, where $n$ is the sample number. $p$ values of less than 0.05 were accepted as significant.

\section{Results}

There were no significant differences in spirometric or arterial blood gas measurements between the diabetic and the control subjects except for $\mathrm{PaCO}_{2}$, which was about $4 \mathrm{~mm} \mathrm{Hg}$ higher in the diabetic patients than in the control group (mean (SD) 41.0 (3.3) $v 37.0$ (3.9) $\mathrm{mm} \mathrm{Hg}$; $\mathrm{p}<0.01)$. $\mathrm{PaO}_{2}$ was similar in the two groups $(91.9(10.6) v 90.5(10.6) \mathrm{mm} \mathrm{Hg})$.

The hypoxic ventilatory response was significantly lower in the diabetic patients $\left(0 \cdot 10 \mathrm{l} / \mathrm{min} / \%\right.$ fall $\left./ \mathrm{m}^{2}\right)$ than in the control group $\left(0.24 \mathrm{l} / \mathrm{min} / \%\right.$ fall $/ \mathrm{m}^{2}$; $\mathrm{p}<0.01$ ) (table 3). The difference in the hypoxic ventilatory response was significant in the men but not in the women. The hypercapnic response was sig-

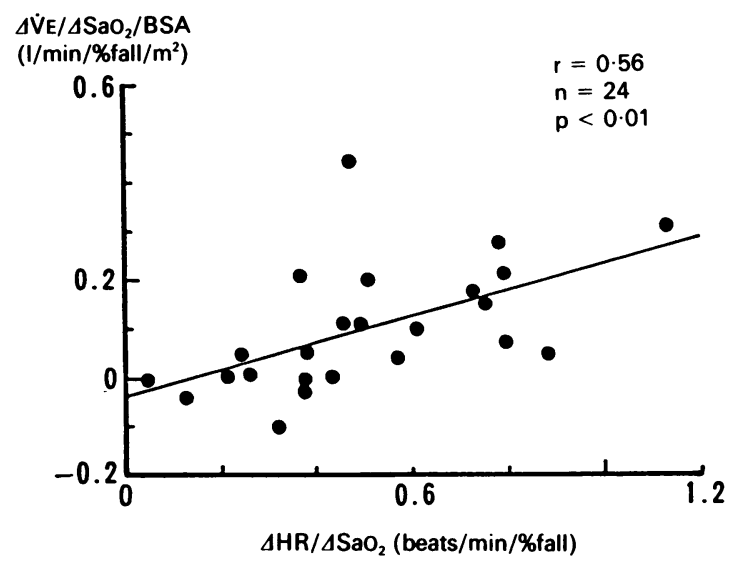

Fig 1 Relation between ventilatory response to hypoxia $\left(\Delta \dot{V} E / \Delta S_{a O} / B S A\right)$ and heart rate response to hypoxia $\left(\Delta \mathrm{HR} / \Delta \mathrm{SaO}_{2}\right)$ in diabetic patients.

Table 3 Ventilatory and heart rate responses in diabetic patients and control subjects (mean (SD) values)

\begin{tabular}{|c|c|c|c|c|c|}
\hline & & $\begin{array}{c}\Delta \dot{V} \mathbf{E} / \Delta \mathrm{Sao}_{2} / \mathrm{BSA} \\
\left(\mathrm{l} / \mathrm{min} / \% \mathrm{fall} / \mathrm{m}^{2}\right)\end{array}$ & 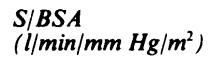 & $\begin{array}{l}B \\
(m m H g)\end{array}$ & $\begin{array}{l}\Delta H R / \Delta \mathrm{SaO}_{2} \\
\text { (beats } / \mathrm{min} / \% \text { fall) }\end{array}$ \\
\hline $\begin{array}{l}\text { Diabetic patients } \\
\text { Normal subjects }\end{array}$ & $\begin{array}{l}\mathbf{M} \\
\mathbf{F} \\
\text { Total } \\
\mathbf{M} \\
\mathbf{F} \\
\text { Total }\end{array}$ & $\begin{array}{l}0.11(0.11)^{* *} \\
0.09(0.15) \\
0.10(0.13)^{* *} \\
0.31(0.24) \\
0.15(0.13) \\
0.24(0.21)\end{array}$ & $\begin{array}{l}1.10(0.41)^{*} \\
1.07(0.87) \\
1.09(0.63)^{*} \\
0.75(0.28) \\
0.77(0.33) \\
0.76(0.30)\end{array}$ & $\begin{array}{l}36.5(3.7) \\
37.6(5.6) \\
36.9(4 \cdot 5) \\
35 \cdot 3(5 \cdot 7) \\
36.2(5.6) \\
35.7(6.7)\end{array}$ & $\begin{array}{l}0.57(0.29)^{* *} \\
0.42(0.20)^{* *} \\
0.51(0.26)^{* *} \\
1.44(0.63) \\
1.05(0.53) \\
1.27(0.61)\end{array}$ \\
\hline
\end{tabular}

BSA - body surface area; $\Delta \dot{V E} / \Delta S_{2}$-slope factor for ventilatory response to hypoxia; $S$-slope factor for ventilatory response to

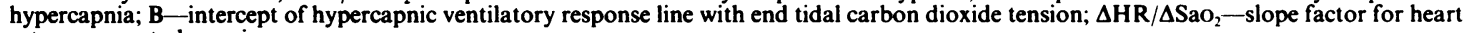
rate response to hypoxia.

${ }^{*} p<0.05,{ }^{*} p<0.01$ in the comparison with normal subjects. 




Fig 2 Relation between ventilatory response to hypoxia $\left(\Delta \dot{V} E / \Delta \mathrm{SaO}_{2} / \mathrm{BSA}\right)$ and heart rate variation during deep breathing $(\triangle H R)$ in diabetic patients. One patient, who had myocardial infarction a week after the tests, was excluded.

nificantly higher in the diabetic patients than in the control group $\left(1.09 v 0.76 \mathrm{l} / \mathrm{min} / \mathrm{mm} \mathrm{Hg} / \mathrm{m}^{2} ; \mathrm{p}<\right.$ 0.05 ); whereas the $\mathrm{B}$ value, the intercept of the hypercapnic ventilatory response line with $\mathrm{P}_{\mathrm{ET}} \mathrm{CO}_{2}$, showed no significant difference (table 3 ).

The heart rate response to hypoxia was significantly lower in the diabetic patients $(0.51$ beats $/ \mathrm{min} / \%$ fall $)$ than in the control group $(1.27$ beats $/ \mathrm{min} /$ $\%$ fall;p $<0.01)$. This held true for men and women separately (table 3 ). There was a significant correlation between the ventilatory response and the heart rate response to hypoxia in the diabetic subjects $(r=0.56$, $\mathrm{p}<0.01$ : fig 1), but not in the control subjects $(\mathrm{r}=0.28)$.

Both the ventilatory response and the heart rate response to hypoxia in the diabetic patients showed a weak but significant correlation with heart rate varia-

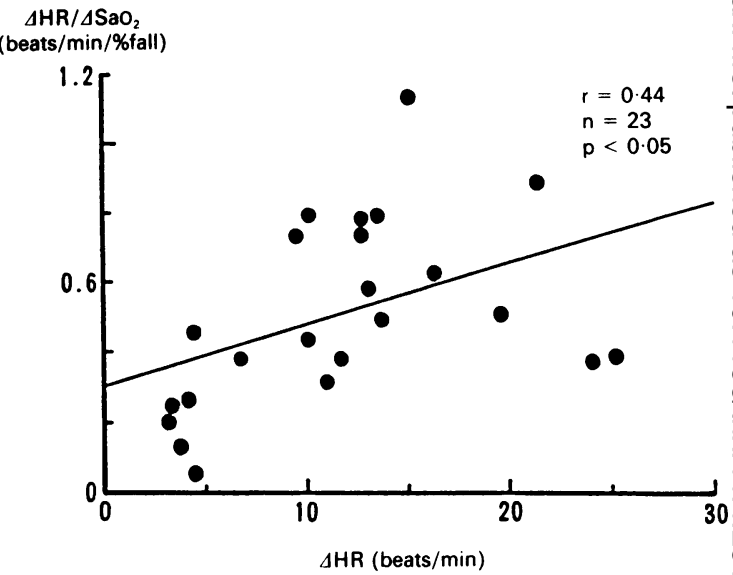

Fig 3 Relation between heart rate response to hypoxia $\left(\Delta \mathrm{HR} / \Delta \mathrm{SaO}_{2}\right)$ and heart rate variation during deep breathing $(\Delta H R)$ in diabetic patients. One patient, who had myocardial infarction a week after the tests, was excluded.

tion during deep breathing $(r=0.45, p<0.05$ for the ventilatory response; fig $2 ; \mathrm{r}=0.44, \mathrm{p}<0.05$ for the heart rate response: fig 3 ), if the results from one patient are excluded (this patient, who had had myocardial infarction one week after the tests had been carried out, had a variation in heart rate during deep breathing of only 4.9 beats $/ \mathrm{min}$, though the ventilatory and heart rate responses to hypoxia were relatively well preserved).

Age; duration of diabetes; insulin dependence or independence; and presence or absence of nephropathy, retinopathy, peripheral neuropathy, and orthostatic hypotension did not have a significant effect on the ventilatory responses to hypoxia or hypercapnia (table 4), nor did degree of glycaemic control. Diabetic patients with nephropathy, peripheral neuropathy, or orthostatic hypotension,

Table 4 Ventilatory and heart rate responses to hypoxia and heart rate variation during deep breathing in diabetic patients (mean (SD) values)

\begin{tabular}{|c|c|c|c|}
\hline Diabetic patients ( $n$ ) & $\Delta \dot{V} \mathrm{E} / \Delta \mathrm{SaO}_{2} / \mathrm{BSA}\left(\mathrm{l} / \mathrm{min} / \% \mathrm{fall} / \mathrm{m}^{2}\right)$ & $\Delta \mathrm{HR} / \Delta \mathrm{SaO}_{2}($ beats $/ \mathrm{min} / \%$ fall $)$ & $\Delta H R($ beats $/ \mathrm{min})$ \\
\hline \multicolumn{4}{|l|}{ Retinopathy } \\
\hline $\begin{array}{l}\text { Positive (11) } \\
\text { Negative (13) }\end{array}$ & $\begin{array}{l}0 \cdot 10(0 \cdot 17) \\
0 \cdot 10(0 \cdot 10)\end{array}$ & $\begin{array}{l}0.46(0.32) \\
0.55(0.20)\end{array}$ & $\begin{array}{r}9 \cdot 6(6 \cdot 8) \\
13 \cdot 1(6 \cdot 1)\end{array}$ \\
\hline \multicolumn{4}{|l|}{ Nephropathy } \\
\hline $\begin{array}{l}\text { Positive (6) } \\
\text { Negative (18) }\end{array}$ & $\begin{array}{l}0 \cdot 09(0 \cdot 18) \\
0 \cdot 10(0 \cdot 11)\end{array}$ & $\left.\begin{array}{l}0.27(0.18) \\
0.59(0.24)\end{array}\right\} p<0.01$ & $\left.\begin{array}{r}4.3(0.5) \\
13.9(5.7)\end{array}\right\} p<0.01$ \\
\hline \multicolumn{4}{|l|}{ Peripheral neuropathy } \\
\hline $\begin{array}{l}\text { Positive (5) } \\
\text { Negative (19) }\end{array}$ & $\begin{array}{l}0.04(0.04) \\
0.12(0.14)\end{array}$ & $\left.\begin{array}{l}0.28(0.16) \\
0.57(0.25)\end{array}\right\} p<0.05$ & $\begin{array}{r}8 \cdot 9(9 \cdot 4) \\
12 \cdot 3(5 \cdot 6)\end{array}$ \\
\hline \multicolumn{4}{|l|}{ Postural hypotension } \\
\hline $\begin{array}{l}\text { Positive (8) } \\
\text { Negative (16) }\end{array}$ & $\begin{array}{l}0.09(0 \cdot 17) \\
0 \cdot 11(0 \cdot 11)\end{array}$ & $\left.\begin{array}{l}0.32(0.16) \\
0.60(0.25)\end{array}\right\} p<0.01$ & $\left.\begin{array}{r}7.0(5.7) \\
13.8(5.8)\end{array}\right\} p<0.05$ \\
\hline $\begin{array}{l}\text { Insulin dependence } \\
\text { Dependent (14) } \\
\text { Not dependent (10) }\end{array}$ & $\begin{array}{l}0.06(0.11) \\
0.15(0.14)\end{array}$ & $\begin{array}{l}0.44(0.25) \\
0.61(0.26)\end{array}$ & $\begin{array}{l}11.2(7 \cdot 1) \\
11.9(5 \cdot 9)\end{array}$ \\
\hline
\end{tabular}

$\Delta \mathrm{HR}$-heart rate variation during deep breathing; see table 3 for $\Delta \dot{\mathrm{VE}} / \Delta \mathrm{SaO}_{2} / \mathrm{BSA}$ and $\Delta \mathrm{HR} / \Delta \mathrm{SaO}_{2}$. 
however, showed a significantly smaller heart rate response to hypoxia or heart rate variation during deep breathing (or both) than did patients without such complications (table 4).

\section{Discussion}

The present study has clearly shown that the ventilatory and heart rate responses to hypoxia are impaired in diabetic patients, whereas the ventilatory response to hypercapnia is well preserved. The ventilatory and heart rate responses to hypoxia were correlated in the diabetic group only, and the responses also showed a weak but significant relation with heart rate variation during deep breathing. Impairment of the ventilatory response to hypoxia was not related to complications of diabetes, such as peripheral neuropathy or nephropathy, whereas the heart rate response to hypoxia and heart rate variation during deep breathing showed a significant relation.

Earlier studies ${ }^{5}$ and the observations of Page and Watkins ${ }^{2}$ suggested that autonomic neuropathy may lead to abnormal ventilatory responses to hypoxia. But several subsequent studies ${ }^{715}$ have failed to find any impairment of the ventilatory response to hypoxia in diabetic patients with clinically evident autonomic neuropathy. There is also conflicting evidence ${ }^{68}$ on whether such patients have abnormally decreased responses to hypercapnia. It is well known that ventilatory responses to hypoxia and hypercapnia vary widely even among normal individuals and that $10-20 \%$ of such subjects are "low responders" to hypoxia. ${ }^{1316}$ Ventilatory responses are influenced by many physiological and environmental factors, such as age, sex, physical characteristics, metabolic rate, exercise, and residence at high altitude, and variation in these factors may explain in part at least why some studies have failed to detect an impaired ventilatory response to hypoxia in diabetic patients. In the present study we randomly selected a relatively large number of diabetic patients with various degrees of diabetic complications, and compared the ventilatory responses with those of age and sex matched control subjects. Soler and Eagleton, ${ }^{8}$ using similar methods, failed to find any appreciable abnormality in the ventilatory responses to hypoxia or hypercapnia in diabetic patients with autonomic neuropathy. The number of subjects in each diabetic group in their study was, however, relatively small, and age and sex ratios were not matched as strictly as in our study. In addition, the resting minute ventilation obtained in their study showed a wide scatter in each group, which may indicate poor reproducibility of their measurements. These factors may explain why, when the mean values were lower in the diabetic group than in the control subjects, the differences in ventilatory response to hypoxia were not significant.

The ventilatory response to hypoxia reflects the function of the afferent and efferent limbs of the reflex arc, including carotid body function and the activity of the respiratory centre. Hypoxia may also cause central depression of ventilation by two possible mechanisms, ${ }^{17-19}$ central hypocapnia resulting from increased cerebral blood flow and metabolic depression of neuronal function. The latter includes a direct reduction in metabolic substrate during severe oxygen restriction and the release and accumulation of neurotransmitters with their net inhibitory effect on synaptic transmission of central respiratory neurones. The insensitivity to hypoxia shown in the present study could therefore be due to several factors. Respiratory muscle dysfunction and abnormal motor descending pathways are the least likely causes, because respiratory function in the diabetic patients was normal and their ventilatory response to hypercapnia was enhanced, indicating that their ability to increase ventilation was well preserved.

One possible explanation for the decreased ventilatory response to hypoxia is that medullary depression of ventilation by hypoxia is greater in diabetic patients than in control subjects. This is supported by the observation ${ }^{20}$ that the control of cerebral blood flow is abnormal in diabetic patients, who show a lack of normal cerebral vasodilatation in response to an increase in arterial $\mathrm{PCO}_{2}$. Hypoxia is a potent stimulus to cerebral vasodilatation and, if this fails to occur, hypoxia may have a more severe metabolic effect on the brain and depress ventilation centrally. On the other hand, however, a lack of cerebral vasodilatation in response to hypoxia may reduce hypoxic ventilatory depression by reducing the washout of carbon dioxide from the brain and thus increasing brain tissue $\mathrm{PCO}_{2}$. Another explanation for the abnormally decreased ventilatory response to hypoxia is carotid body dysfunction or abnormal sensory input to respiratory neurones as a result of autonomic neuropathy. Our study showed a weak but significant relation between the ventilatory response to hypoxia and heart rate variation during deep breathing. The latter is reported to be a simple measure of autonomic nervous dysfunction in diabetic patients. ${ }^{21}$ Although several other bedside tests use the heart rate as an index, this test has been reported to be the most sensitive ${ }^{22} 23$ and easy to interpret because, as it is performed during quiet, nonstressed supine rest, ${ }^{24}$ it assesses only parasympathetic nervous function. Unfortunately, we do not have control values for this test. There are some well established predicted values for normal healthy subjects, however. If we use the age dependent lower limit of the $90 \%$ confidence interval reported by Wieling et $a l,{ }^{25}$ values in 15 out of 23 patients in the present study fall into the abnormal range. 
The heart rate response to hypoxia is more difficult to interpret. The effect of hypoxia on the cardiovascular system is mediated through the interaction of several opposing influences. The bradycardia resulting from carotid body chemoreceptor stimulation is opposed by cardioaccelerator reflexes from lung inflation receptors stimulated as a result of hyperventilation and from hypoxia of the central nervous system. ${ }^{26}{ }^{27}$ The increase in mean arterial blood pressure resulting from hypoxia may also stimulate the baroreflexes and thereby contribute to cardiac slowing. In addition, there is accumulating evidence ${ }^{27} 28$ that the aortic chemoreceptors may cause tachycardia rather than bradycardia. As a result, hypoxia leads to an increase in heart rate in conscious man that is linearly related to arterial oxygen saturation. ${ }^{14} \mathrm{Al}$ though the heart rate response appears to be closely related to the ventilatory response to hypoxia, neither two previous studies ${ }^{149}$ nor the present study have found any significant correlation between the two responses in normal, healthy subjects. It is hard to determine from our study which particular lesion is responsible for the abnormal heart rate response to hypoxia in diabetic patients. Our results may reflect abnormal metabolic changes in the brain during hypoxia or another manifestation of autonomic neuropathy, as there was a significant correlation between the ventilatory and heart rate response to hypoxia in the diabetic group only.

Finally, the ventilatory response to hypercapnia in diabetic patients was increased in the present study. There was no convincing evidence that this was related to diabetic neuropathy, as no relation was found between the ventilatory response to hypercapnia and any index of diabetic neuropathy. $\mathrm{PaCO}_{2}$ was higher in the diabetic patients than the control subjects but this does not explain the augmented hypercapnic response; the higher $\mathrm{PaCO}_{2}$ in diabetic patients with normal pH should depress the ventilatory response to hypercapnia rather than enhance it. One hypothesis is that a lack of normal cerebral vasodilatation in response to hypercapnia ${ }^{18}$ might induce severe brain tissue acidosis under hypercapnic challenge in diabetic patients, but this requires confirmation. The recent debate has been whether hypercapnic sensitivity is impaired in patients with diabetes. ${ }^{68}$ Our findings show that they have a well preserved ventilatory response to hypercapnia.

In conclusion, we have shown that the ventilatory and heart rate responses to hypoxia are impaired in diabetic patients. This may be a manifestation of autonomic neuropathy or may be due to abnormal metabolic changes in the brain during hypoxia. The ventilatory response to hypercapnia was not impaired.

We thank Mrs Mari Nishimura for typing the text. This work was supported by a research grant (No
62480200) from the Ministry of Education, Science, and Culture, Japan.

\section{References}

1 Ewing DJ, Campbell IW, Clarke BF. The natural history of diabetic autonomic neuropathy. $Q J$ Med 1980;49:95-108.

2 Page MMcB, Watkins PJ. Cardiorespiratory arrest and diabetic autonomic neuropathy. Lancet 1978;i:14-6.

3 Srinivasan G, Sanders G. Cardiorespiratory arrest in diabetes. Lancet 1978;i:935.

4 Rees PJ, Cochrane GM, Prior JG, Clark TJH. Sleep apnea in diabetic patients with autonomic neuropathy. $J R$ Soc Med 1981;74:192-5.

5 Courtenay-Evans RJ, Benson MK, Hughes DTD. Abnormal chemoreceptor response to hypoxia in patients with tabes dorsalis. Br Med J 1971;i:530-1.

6 Homma I, Kageyama S, Nagai T, Taniguchi I, Sakai T, Abe M. Chemosensitivity in patients with diabetic neuropathy. $\mathrm{Clin} \mathrm{Sci}$ 1981;61:599-603.

7 Calverley PMA, Ewing DJ, Campbell IW, et al. Preservation of the hypoxic drive to breathing in diabetic autonomic neuropathy. Clin Sci 1982;63:17-22.

8 Soler NG, Eagleton LE. Autonomic neuropathy and the ventilatory responses of diabetics to progressive hypoxemia and hypercarbia. Diabetics 1982;31:609-14.

9 Williams JG, Morris AI, Hayter RC, Ogilvie CM. Respiratory responses of diabetics to hypoxia, hypercapnia and exercise. Thorax 1984;39:529-34.

10 Ferris BG Jr, Anderson DO, Zickmantel R. Prediction values for screening tests of pulmonary function. Am Rev Respir Dis 1965;91:252-61.

11 Berglund E, Birath G, Bjure J. Spirometric studies in normal subjects. I. Forced expirograms in subjects between 7 and 70 years of age. Acta Med Scand 1963;173:185-92.

12 Kawakami Y, Asanuma Y, Yoshikawa T, Shida A, Murao M. A control system for arterial blood gases. J Appl Physiol 1981;50:1362-6.

13 Hirshman CA, McCullough RE, Weil JV. Normal values for hypoxic and hypercapnic ventilatory drives in man. $J A p p l$ Physiol 1975;38:1095-8.

14 Slutsky AS, Rebuck AS. Heart rate response to isocapnic hypoxia in conscious man. Am J Physiol 1978;234:129-32.

15 Ewing DJ, Campbell IW, Calverley PWA, Fraser DM, Clarke BF Natural history of diabetic autonomic neuropathy. $Q \mathrm{~J} \mathrm{Med}$ 1979;48:660-2

16 Yamamoto $H$, Yoshikawa $T$, Nishimura M, et al. Values for ventilatory responses in Japanese and analyses of physiological factors [in Japanese]. Jpn J Thorac Dis 1982;20:408-13.

17 Cherniack NS, Edelman NH, Lahiri S. Hypoxia and hypercapnia as respiratory stimulants and depressants. Respir Physiol 1970;11:113-26.

18 Neubauer JA, Santiago TV, Posner MA, Edelman NH. Ventra medullary $\mathrm{pH}$ and ventilatory responses to hyperperfusion and hypoxia. J Appl Physiol 1985;58:1659-68.

19 Nishimura M, Suzuki Y, Nishiura Y, et al. Effect of brain blood flow on hypoxic ventilatory response in humans. J Appl Physiol 1987;63:1100-6.

20 Dandona T, James IM, Newbury PA, Woolard NL, Beckett AG Cerebral blood flow in diabetes mellitus; evidence of abnormal vascular reactivity. Br Med J 1978;ii:325-6.

21 Watkins PJ, Mackay JD. Cardiac denervation in diabetic neuropathy. Ann Intern Med 1980;92:304-7

22 Mackay JD, Page MMcB, Cambridge J. Watkins PJ. Diabetic autonomic neuropathy: the diagnostic value of heart rate monitoring. Diabetologia 1980;18:471-8.

23 Dryberg T, Benn J, Christiansen JS, Hilsted J, Nerup J. Prevalence of diabetic autonomic neuropathy measured by simple bedside tests. Diabetologia 1981;20:190-4. 
24 Pfeifer MA, Cook D, Brodsky J, Tice D, Reenan A, Swedine S, Halter JB, Porte D Jr. Quantitative evaluation of cardiac parasympathetic activity in normal and diabetic man. Diabetes 1982;31:339-45.

25 Wieling W, van Brederode JFM, de Rijk LG, Borst C, Dunning AJ. Reflex control of heart rate in normal subjects in relation to age: a data base for cardiac vagal neuropathy. Diabetologia 1982;22:163-6.

26 Korner PI, Shaw J, West MJ, Oliver JR, Hilder RG. Integrative reflex control of heart rate in the rabbit during hypoxia and hyperventilation. Circ Res 1973;33:63-73.

27 Pisarri TE, Kendrick JE. Reduced effectiveness of the carotid baroreflex during arterial hypoxia in dogs. Am J Physiol 1984;247:623-30.

28 Karim F, Hainsworth R, Sofola OA, Wood LM. Responses of the heart to stimulation of aortic body chemoreceptors in dogs. Circ Res 1980;46:77-83.

29 Kronenberg RS, Drage CW. Attenuation of the ventilatory and heart rate responses to hypoxia and hypercapnia with aging in normal men. J Clin Invest 1973;52:1812-9. 